\title{
El arte de la política / la política del arte: Semprún y Padura ante el asesinato de Trotsky
}

The Art of Politics / Politics of Art: Semprún and

Padura Faced with the Murder of Trotsky

A arte da política / a política da arte: Semprún e

Padura ante $o$ assassínio de Trotsky

\section{Ana María Amar Sánchez}

UNIVERSITY OF CALIFORNIA, IRVINE

Profesora de literatura latinoamericana y teoría literaria en University of California, Irvine. Doctora en Letras de la Universidad de Buenos Aires. Ha publicado numerosos artículos en revistas y antologías de la especialidad. Es autora de tres libros: El relato de los hechos. Rodolfo Walsh: testimonio y escritura (Ediciones de la Flor, 2008 2ed.), fuegos de seducción y traición. Literatura y cultura de masas (Beatriz Viterbo Editora, 2000), e Instrucciones para la derrota. Narrativas éticas y políticas de perdedores (Anthropos, 2010). Correo electrónico: aamarsan@uci.edu 


\section{Resumen}

El artículo analiza el entramado entre estética y política en relatos que giran en torno al acontecimiento histórico que fue la muerte de Trotsky: La segunda muerte de Ramón Mercader, de Jorge Semprún; El hombre que amaba a los perros, de Leonardo Padura, y la sección "La muerte de Trotsky referida por varios escritores cubanos, años después -o antes-", perteneciente a Tres tristes tigres de Cabrera Infante. A pesar de la diversidad de estéticas (distintas relaciones con la referencialidad y disímiles proyectos formales), los textos parecen tener coincidencias político-ideológicas, y en todos el desencanto clausura las utopías políticas.

Palabras clave: política, estética, forma literaria, historia.

Palabras descriptor: Estética literaria, formas literarias, política y literatura, historia.

\section{Abstract}

The article analyzes the structural framework between aesthetics and politics in stories that revolve around an historical event: the death of Trotsky. The second death of Ramon Mercader, by Jorge Semprún; The man who loved dogs, by Leonardo Padura, and the section "La muerte de Trostsky referida por varios escritores cubanos, años después -o antes-", that belongs to Three Trapped Tigers by Cabrera Infante. Despite the diversity of aesthetic visions (different relationships with referentiality and dissimilar formal projects), the texts seem to have political and ideological coincidences, and in all of them the disenchantment concludes the political utopias.

Keywords: politics, aesthetics, literary form, history. Keywords plus: Literature, aesthetics, literary form, politics and literatura, history.

\section{Resumo}

$\mathrm{O}$ artigo analisa a trama entre estética e política em relatos que giram em torno do evento histórico que foi a morte de Trotsky: La segunda muerte de Ramón Mercader (A segunda morte de Ramón Mercader), de Jorge Semprún; El hombre que amaba a los perros (O homem que amava os cães), de Leonardo Padura, e a seção "La muerte de Trotsky referida por varios escritores cubanos, años después -o antes-" (Morte de Trotsky referido por vários escritores cubanos, anos depois - ou antes), pertencente a Tres tristes tigres (Três tristes tigres) de Cabrera Infante. Embora a diversidade de estéticas (diferentes relações com a referencialidad e dissimiles projetos formais), os textos parecessem tiver coincidências político-ideológicas, e em todos o desencanto clausura as utopias políticas.

Palavras-chave: política, estética, forma literária, historia.

Palavras-chave descritores:

Estética literária, formas

literárias, política ea literatura, história.

RECIBIDO: 3 DE MAYO DE 2013. EVALUADO: 15 DE JUNIO DE 2013. ACEPTADO: 15 DE JUNIO DE 2013.

Cómo citar este artículo:

Amar Sánchez, Ana María. "El arte de la política / la política

del arte: Semprún y Padura ante el asesinato de Trotsky".

Cuadernos de Literatura 18. 35 (2014): 247-258. 
LAS RELACIONES ENTRE literatura, ética y política siempre han sido objeto de debate y análisis por parte de la crítica. Este vínculo ha estado presente en mis trabajos y, en especial, mi estudio sobre los perdedores se enfocó en un corpus en el que se privilegiaron distintas inflexiones de la pérdida y estableció una constelación de textos ligados por sus representaciones de la experiencia de derrota, entre ellos había notables distancias, era posible establecer diferencias que iban de la sutileza y complejidad de un cuento de Borges a las novelas más convencionales. Hay que subrayar que el contacto con la política en estos relatos no invalidaba su específica condición estética. Sus disímiles cualidades literarias no dependían de ese nexo: la narrativa analizada proponía, con independencia de los valores estéticos de cada caso particular, diversas articulaciones con la ética y la política.

Justamente esas disímiles cualidades literarias de los textos de aquel corpus llevan a considerar, casi como una continuación lógica, las relaciones entre estética y política; es decir, parece imponerse una reflexión que incorpore los problemas y tensiones entre ambas. Si, como afirma Rancière, "no hay ningún conflicto entre la pureza del arte y su politización. Al contrario, en función de su pureza la materialidad del arte se propone como materialidad anticipada de una configuración distinta de la comunidad" (Sobre políticas 27), podemos pensar que la literatura, ya sea en su formas más explícitas o más elusivas, intenta una configuración diferente. La cuestión será cómo diseña esas configuraciones, qué tipo de soluciones encuentra al intento de fusionar lo político con una forma estética específica ${ }^{1}$. En otro estudio, "Las paradojas del arte político", Rancière insiste en este vínculo y sostiene que "un arte crítico es un arte que sabe que su efecto político pasa por la distancia estética" (84), es decir, "lo que se llama política del arte es el entrelazamiento de lógicas heterogéneas" (66).

Un acontecimiento, en el sentido que da al término Badiou ${ }^{2}$, parece haber tenido la virtud de anudar lo político (e histórico) con lo literario de un modo

1 Coincido con Donoso Macaya, quien también cita a Rancière en su estudio sobre Bolaño, y señala que "es posible percibir la existencia de un territorio común a la literatura y a la política: ese territorio común es el territorio de la estética" (126).

2 Alain Badiou llama acontecimiento a esa situación que exige una toma de decisión del sujeto para sostener la memoria de lo ocurrido y la propia identidad; un hecho que marca un antes y un después. De acuerdo con su postura, el acontecimiento rompe con la historia, marca un antes y un después, de manera que nada vuelve a ser igual. Es una situación colectiva que muestra lo que una época tiene de intolerable, pero también hace emerger posibilidades de vida. Tiene que ver con la historia de la política, no con la del Estado, y la asunción de una postura frente a él permite no ceder ni confundirse; es decir, abre alternativas, emergen de él nuevos procesos, de algún modo genera nuevas opciones políticas. 
notable: el asesinato de Trotsky el 22 de agosto de 1940 en la ciudad de México generó numerosas consecuencias. Es la culminación de un terrible acoso que marca el fin definitivo de un proyecto y abre un largo proceso que quizá no ha concluido: es un acontecimiento, un hito en la historia política de la izquierda (y de la derecha). Pero no solo es un episodio clave en la historia del siglo XX que funciona como un punto de inflexión para muchos intelectuales, en tanto escinde al Partido Comunista de otras organizaciones izquierdistas, sino que también da origen a varios textos literarios, en los que se cruzan de modo preciso lo político y lo estético. Se trata de una literatura conformada en la fusión de esos elementos: es imposible excluir lo político de ella pero también lo es excluir la consideración de cada proyecto estético particular que da forma, organiza y produce el sentido político. Esta ligazón está en el origen de esos relatos: todos se ocupan de la muerte de Trotsky, del hecho mismo, y, a la vez, parecen la cita de uno de sus textos: La revolución traicionada. Acontecimiento y escritura conforman novelas que escriben o reescriben dos cosas: un asesinato y una traición; es decir, están presentes allí tanto lo factual como lo discursivo. Ambos, muerte y escritura, dan origen entonces a una literatura que, desde estéticas diferentes, se ocupa del destino de un hombre que encarna una revolución y, especialmente, una revolución traicionada.

Sin duda, la última novela de Leonardo Padura, El hombre que amaba a los perros, es un ejemplo paradigmático de un proyecto estético que se plantea abiertamente como político. Su misma trayectoria como autor de policiales lo liga a una tradición del género que se ha politizado en América Latina desde los relatos de Rodolfo Walsh y su fusión del testimonio con el código detectivesco. En la mayoría de los textos de Padura este código estructura la búsqueda de la verdad, el consiguiente desencanto por la imposibilidad de justicia, la derrota del héroe. Sin embargo, en El hombre que amaba a los perros (2009), aunque se trata también de una investigación que busca una verdad oculta para la que toda justicia se vuelve improbable y en la que el fracaso del protagonista es radical, el relato se aleja del código y lleva a otras conexiones literarias. Diría que la estructura del policial abandona el plano argumental y pasa a sostener el texto mismo en la forma de sucesivas indagaciones en torno a lo silenciado; es decir, se vuelve un problema de la escritura, ya no de la historia contada. Y es aquí donde el contacto entre política y estética parece pasar a primer plano.

Asimismo, la novela de Padura remite a otras del pasado: sin duda, nos lleva a recordar la sección "La muerte de Trotsky referida por varios escritores cubanos, años después -o antes-" perteneciente a Tres tristes tigres de Cabrera Infante, publicada por primera vez en 1965 . A su vez, se encuentra ligada tanto 
por lo temático como por ciertos aspectos estéticos con La segunda muerte de Ramón Mercader de Jorge Semprún, texto de cruce, escrito originalmente en francés ([1969] 1970) por un autor español, con una problemática española y una estética indudablemente francesa.

Revolución y traición, en sus acepciones políticas y literarias, están presentes en la obra de Cabrera Infante, novela experimental, revolucionaria, de la que la política parece expurgada luego de su partida de Cuba. Sin embargo, el fragmento mencionado la reintroduce y nos recuerda de inmediato el mencionado ensayo de Trotsky: por una parte, debido a la confrontación que lleva a Cabrera al exilio; por otra, porque la sección es un conjunto de parodias de escritores cubanos sobre el mismo tema: la muerte del exilado ruso. Es entonces también un ajuste de cuentas -y una "traición"- del autor a su tradición literaria. La novela, como se sabe, explora todas las posibilidades del concepto de traición en la escritura: como traducción, parodia, duplicación ${ }^{3}$. De este modo, el fragmento traiciona -duplica, repite, traduce, destruye- el canon literario cubano en su parodia; lo traiciona contando otra traición, la política. Es interesante notar que, si bien el relato se ha destacado por un trabajo exasperado de relaciones intertextuales con la literatura y el cine, las parodias incluidas en este fragmento son exclusivamente de textos cubanos canónicos: Martí, Lezama Lima, Carpentier, Piñera, Cabrera, Novás, Guillén. Los títulos y la casi grotesca imitación del estilo de cada autor hacen pensar en una parodia con una fuerte impronta destructiva; rasgo que se acentúa en el cierre del fragmento con el "poema" a Stalin, los juegos de palabras (Lupanarsky por Lunacharsky) y las absurdas escenas en el Kremlin ${ }^{4}$. La novela de Cabrera Infante establece así una apretada red en diversos niveles; una fusión entre las estrategias literarias y las políticas, entre las diversas traiciones (la traición al canon se construye narrando la traición política a Trotsky y a la revolución), que nos remite a los otros relatos ya mencionados.

La segunda muerte de Ramón Mercader se inscribe en una tradición estética cercana a la de Tres tristes tigres. Todos la hemos leído como un texto nouveau roman, como una perfecta novela objetivista, movimiento al que Semprún

3 Son numerosos los trabajos críticos que han leído Tres tristres tigres como una parodia en la que tienen un papel esencial los juegos de palabras, la cita, el humor, la referencia en clave; es decir, ha sido considerada como un caso ejemplar de relato que lleva a su máxima expresión los proyectos experimentales de la narrativa de los años sesenta.

4 "[...] saca del busto las obras completas de Marx, Engels y Lenin, una lupa y una cuchara. Pone los libros en el piso, con la lupa y el sol de medianoche ruso logra hacer fuego sobre ellos y calienta el aceite de ricino. Luego trata, inútilmente, de dar una cucharada del purgante a Stalin, que forcejea, patalea, se suelta y sigue corriendo Kremlin abajo [...]" (255). 
siempre se ha sentido cercano ${ }^{5}$. No hay duda de que puede hacerse un verdadero inventario de sus técnicas: el juego de duplicaciones, las incertidumbres en la trama y los personajes. En particular, el sujeto de enunciación, ese narrador que comenta sobre las alternativas novelescas y el hacer de la escritura en un gesto muy autorreflexivo ${ }^{6}$, acentúa el juego de ambigüedades al entrecruzar a la familia Semprún con la trama ficcional: abundan las alusiones a episodios de la vida del autor y de su padre, miembro del Gobierno republicano español, supuestamente relacionado con el padre del protagonista. De hecho, ese sujeto podría ser pensado como un álter ego del autor. Esto se ha leído siempre como un juego de ficción/realidad, característico del nouveau roman, de su modo de incluir y diluir lo referencial en el juego antirrealista y antirrepresentativo. No parece casual que el único personaje que desconoce toda la oscura intriga y está por completo fuera del tema político se llame Boutor, en una directa alusión al autor de La modificación, notorio miembro del grupo ${ }^{7}$.

La novela de Padura parece estéticamente muy lejana a la de Semprún; sin embargo, una mirada atenta comienza a encontrar numerosos puntos en común que no se limitan a lo temático. En El hombre que amaba a los perros se entrecruzan tres historias y tres investigaciones: dos de ellas íntimamente vinculadas a la Historia (con mayúscula), las que se enfocan en Trotsky y en Ramón Mercader, su asesino $^{8}$. En ambas, y en especial en la primera, el lector puede encontrar los rastros de una investigación exhaustiva y una fuerte presencia del discurso histórico como referencia dominante. De hecho, la reseña de Javier Goñi en el suplemento Babelia de El País la llama "pormenorizada reconstrucción [...] como si Padura no hubiera acertado a manejar la mucha documentación" y habla de "un exceso de datos" (8). La tercera historia tiene un protagonista y narrador ficcional que nos remite al narrador de Semprún por el ambiguo efecto del vínculo entre ficción y referencia. Claro está que la diversidad de estéticas -el nouveau roman por

5 Incluso en su último relato, Veinte años y un día, sigue viéndose esta filiación.

6 Se multiplican los ejemplos de autorreflexión característica del código nouveau roman: "¿Por qué dejé que el fantasma de Brouwer se instalara en este relato? No había previsto en absoluto esta aparición [...]. Pero el fantasma de Brouwer vino a interponerse, haciendo imposible todo alarde de bravura descriptiva" (55-58); "[...] un número de lectores que el autor no pretende en absoluto conquistar con esta tercera novela" (106); "el único de mis personajes que tal vez ignorase totalmente los enredos de esta historia [...]" (127).

7 Michel Butor ha sido un miembro destacado del movimiento nouveau roman y su novela $L a$ modificación (1960) es paradigmática de esa estética.

8 Un punto de contacto es también el vínculo sesgado con el policial en ambos relatos, presente en el "nouveau roman" y por supuesto en las novelas de Padura: diversos abordajes del misterio, la investigación, el suspenso estructuran la trama en ambas tradiciones literarias. 
un lado y un relato con fuerte impronta histórica por el otro- parece producir un resultado distinto: muchos lectores estarían dispuestos a considerar la novela de Padura un claro relato político y La segunda muerte como una historia de espías con suspenso, en la que lo político (la guerra civil española, la muerte de Trotsky y los oscuros manejos del PC) es un elemento más de la trama que contribuye a su complejidad y ambigüedad.

Sin embargo, las estrategias narrativas tienen puntos de contacto: en particular, el narrador-protagonista de Padura produce la misma confusión y mezcla con lo referencial que generaban las alusiones a Semprún en la novela anterior. En ambas, los datos que el lector posee de los autores funcionan como un guiño; dan lugar a algo similar a lo que Manuel Alberca y Alicia Molero de la Iglesia llaman autoficción; Santiago Morales-Rivera, simulacro autobiográfico, y Julio Premat, ficción de autor ${ }^{9}$. En El hombre que amaba a los perros el narrador nos señala su interés por el género policial y su fascinación por Chandler, del que sale el título del libro: hay que recordar que "El hombre que amaba a los perros" es un cuento de la colección Asesino en la lluvia del autor norteamericano. Se trata de otra clara conexión con el relato policial, en este caso un clásico que ha sido fundamental en el desarrollo del género en Latinoamérica; pero sobre todo la alusión a "mi amigo y congénere Mario Conde" (488), detective protagonista de la mayoría de las novelas de Padura, es un claro gesto cómplice que el lector de Alberca denominaría un pacto ambiguo. Ese narrador, Iván, se delinea como un doble de Conde (como él está en busca de una verdad y lo espera la derrota), pero también es un doble del "autor Padura", quien cierra todas las historias, las búsquedas y los fracasos en la nota final en la que de algún modo se equipara a Iván. Es decir, el personaje de Iván y el autor Padura establecen un constante equilibrio inestable entre la referencia simultánea a lo histórico-político y a la escritura: el sujeto narrador, que parece duplicarse en el autor, articula el "adentro" y el "afuera" de la historia; sin duda, él es el espacio de encuentro entre ficción, biografía, historia y política.

Entonces, en ambos casos -en Semprún y en Padura- encontramos, a pesar de la diferencia entre las estéticas a las que pertenecen los relatos, un sujeto narrador complejo, problemático, punto de cruce entre ficción y referencialidad y, posiblemente -y esta es mi hipótesis-, punto de cruce entre política y estética, entre referencia y autorreferencia. La reiteración de esta figura que parece fusionar

9 Numerosos estudios avalan el interés de la crítica contemporánea -y de la teoría- por esta estrategia narrativa en los últimos años: los trabajos citados de Premat, Alberca, Molero de la Iglesia y Morales-Rivera están dedicados en especial a la literatura latinoamericana y española. 
autor/narrador/personaje en mucha de la narrativa de los últimos años no implica, por supuesto, volver a la categoría de autor, sino analizar el sentido y la función de esta compleja y peculiar figura a la que Premat, en el trabajo antes mencionado, considera un espacio para "proponer soluciones dinámicas", donde se construye "un relato pero también una coherencia, una dialéctica identitaria del que escribe" (12). Sin negar esta postura, creo que en la narrativa reciente ese espacio es un lugar privilegiado donde poner en escena, representar, la tensión entre política y textualidad ${ }^{10}$. Podría pensarse que un texto como el de Padura recoge la herencia de relatos experimentales como el de Semprún, por un lado, y de la tradición detectivesca, por el otro, las utiliza y transforma.

El hombre que amaba a los perros es una ficción, pero dos de sus tres secciones llevan al lector a olvidar esto y se leen como biografías o novelas históricas ${ }^{11}$. A su vez, pueden encontrarse en ella otros procedimientos característicos de una narrativa autorreferencial, más que histórica o testimonial, cercana a la de Semprún: identidades que se duplican y confunden entre sí, personajes que son condensaciones o sinécdoques de momentos históricos, y repeticiones que producen el efecto de espejo entre las tres secciones. A esto hay que añadir que ambas novelas están vinculadas en lo temático, no solo porque hablan del mismo acontecimiento, sino por la elección del tratamiento y el sentido que resulta de sus representaciones. Por ejemplo, los fragmentos de La segunda muerte en los que el guionista de cine plantea su proyecto de película enfocado en Mercader parecen un resumen de la sección dedicada al asesino de Trotsky en Padura: las mismas escenas y, sobre todo, la misma evaluación de su militancia en el PC y del sinsentido de su vida. En la novela de Semprún leemos: "No había sido un militante sacrificado a una violencia necesaria. Solamente un criminal [...]. Había elegido, por su silencio, continuar manteniendo la ficción de esa comunidad carismática" (145). El fragmento se expande y constituye el punto clave del relato

10 El desarrollo de este aspecto excede el propósito de este trabajo, pero quisiera señalar que es particularmente interesante en la medida en que se ha vuelto frecuente en la literatura contemporánea, en la que esta estrategia plantea un nuevo juego de ficción-realidad, con el que parece cuestionar las perspectivas ya aceptadas sobre las categorías de narrador y autor. Lo desarrollo de forma más extensa en el artículo "Máscaras y simulacros: nuevas políticas del sujeto y la narración".

11 En la "Nota muy agradecida" que cierra la novela de Padura leemos: "me atuve con toda la fidelidad posible (recuérdese que se trata de una novela [...]) a los episodios y la cronología de la vida de León Trotski [...]. Este ejercicio entre realidad verificable y ficción es válido para el caso de Mercader como para el de otros muchos personajes reales que aparecen en el relato novelesco -repito: novelesco- y por lo tanto organizado de acuerdo con las libertades y exigencias de la ficción" (571). 
sobre Mercader en Padura. Del mismo modo, escenas de La segunda muerte, como su llegada a la casa de Trotsky y la conversación con su mujer, parecen una sinopsis que desarrolla El hombre que amaba a los perros.

Tanto en el relato de Semprún como en el de Padura se multiplican las voces y los protagonistas -también en el de Cabrera Infante, en la medida en que toda parodia implica cruce, lucha, encuentro de enunciaciones diversas-, las identidades ambiguas, dobles y triples. A su vez, esas voces tejen una trama compleja de historias que se desarrollan a través de numerosas escrituras. En el caso de El hombre que amaba a los perros están los papeles de Mercader, la biografía escrita por su hermano, el relato de Iván, el de su amigo Daniel luego de su muerte y la nota del autor Padura que clausura y enmarca todas las versiones. Por su parte, en La segunda muerte el narrador acumula perspectivas, puntos de vista, personajes "falsos" (la doble identidad de Mercader y la del protagonista que utiliza el mismo nombre, es decir, hay dos Mercader igualmente falsos) a través de cartas, historias, proyectos de film, fragmentos de periódicos, libros, etc. Es imposible para el lector olvidar que está leyendo textos construidos con capas de discursos que conforman una especie de palimpsesto. En un doble juego las novelas insisten en esta condición ficcional y narrativa, a la vez que se vuelven -justamente a través de la reafirmación constante de esa escritura- hacia la referencia histórica.

Desde el punto de vista de la representación del acontecimiento y sus posibles sentidos, del modo de verlo ${ }^{12}$, la perspectiva es, sin duda y siempre, desde Cabrera Infante a Padura, el resultado de una mirada en la que la historia cobra sentido a partir de una relación entre un presente y su pasado. En Tres tristes tigres, la parodia literaria fusiona el asesinato con la traición que define los resultados revolucionarios en la Cuba que abandona Cabrera Infante. La segunda muerte de Ramón Mercader constituye una lectura del fracaso de un proyecto histórico en manos de la burocracia stalinista; otra vez se trata de la traición del PC europeo convertido en un mundo de espías que poco se diferencian de los de la CIA, para quienes impera "el desprecio fundamental hacia los hombres, válvulas tapadas, pequeños tornillos, engranajes minúsculos, y siempre reemplazables, del gran aparato" (263). A su vez, la sección dedicada al narrador Iván en El hombre que amaba a los perros condensa los tres episodios (el de Trotsky, el de Mercader y el del personaje cubano), y los diferentes tiempos y momentos políticos revolucionarios en los que el PC stalinista parece haber torcido un mismo

12 Cabe citar aquí el clásico texto de John Berger, Modos de ver: "Nunca miramos solo una cosa; siempre miramos la relación entre las cosas y nosotros mismos" (14). 
proyecto: Rusia, la guerra civil española y Cuba. Iván encarna el derrumbre de las ilusiones que sostuvieron los tres procesos (de hecho, muere al desplomarse el techo de su casa casi derruida); su encuentro con Mercader es el episodio pivote que permite la fusión de las historias. Ahí es cuando el personaje descubre su miedo, unido siempre al temor de escribir la historia, miedo que alcanza al autor Padura en la nota final: "Cinco años de dudas y miedos (¿irecuerdan a Iván?)" (573). En este cierre el autor Padura sufre, frente a la escritura de su novela, la misma incertidumbre que Iván, casi su doble, su simulacro autobiográfico ${ }^{13}$. Es constante el debate interno del protagonista acerca de la posibilidad de escribir el texto -la novela- que cierra su amigo Daniel luego de su muerte en el capítulo "Requiem", y que completa y enmarca la nota final del autor. Sin duda, las coincidencias entre ambos y la confluencia de biografía y ficción generan "un efecto de verdad" en el texto. Miedo, escritura, desencanto y naufragio (la imagen de un madero encontrado en la playa se vuelve recurrente) han definido la vida de Iván que es una sinécdoque, una metáfora de su generación -la misma que la del autor Padura- en Cuba.

En todos los casos, la muerte de Trotsky es el episodio político, histórico y literario a partir del cual pensar un presente. El asesinato como una traición al proyecto revolucionario desencadena relatos que lo leen como el epítome de una trayectoria cuyas consecuencias todavía se están desarrollando. En todos los relatos, las profecías de Trotsky, como señala el narrador de Padura, "acabaron cumpliéndose" (488), y la revolución fue traicionada, tal como lo anunciaba el ensayo de 1937 que está en el origen de estas ficciones.

Podríamos concluir que, a pesar de la diversidad de sus estéticas, fácil de observar para cualquier lector, comparten estrategias narrativas, se sostienen en proyectos crítico-ideológicos coincidentes y se parecen notablemente en sus evaluaciones políticas. La relación con la referencialidad, lo explícito o no del relato y la forma estética no definen la politicidad o no de las novelas. El texto nouveau roman es, en este sentido, tan referencial como el de Padura: si confrontamos ambos finales puede verse que La segunda muerte revierte abiertamente sobre la historia y el futuro, mencionando a Trotsky, Natacha y Mercader, y se cierra con una duda que es una postura frente a los hechos: "¿Se secará la sangre, un día? No es seguro" (341). De algún modo hace lo mismo que la nota final de El hombre

13 "Percibí, como una necesidad visceral de aquella historia, la existencia de otra voz, otra perspectiva, capaz de complementar y contrastar lo que me había contado el hombre que amaba a los perros" (408). "Voy a terminar de escribir cómo lo conocí y por qué no me atreví desde el principio a contar su historia" (562). "¿Sabes para qué te contó su historia y después hizo esta carta?... Pues para que tú lo escribieras y lo publicaras [...]" (563). 
que amaba a los perros, en la que Padura, el autor, afirma que en "la perversión de la gran utopía del siglo XX, ese proceso en el que muchos invirtieron sus esperanzas, tantos hemos perdido sueños, años y hasta sangre y vida" (571). Las dos narraciones, las dos ficciones, clausuran las mismas ilusiones con las mismas dudas y el mismo desencanto: la novela de Semprún parece anunciar la desilusión de los años ochenta y noventa, época en que transcurre el relato de Padura. La distancia estética parece entonces reducirse: Rancière tiene toda la razón cuando sostiene que la voluntad de repolitizar el arte se manifiesta en estrategias y prácticas muy distintas. Sin embargo, "en el término de todo un siglo de supuesta crítica de la tradición mimética, es preciso constatar que esa tradición continúa siendo dominante hasta en las formas que se pretenden artística y políticamente subversivas" (Sobre políticas 54 ).

Es posible que sea útil a la crítica actual abandonar el intento de diluir y borrar las diferencias pensando que ya no hay literatura, que todos los discursos son intercambiables, que han cambiado los medios de producción y que todo debate estético es obsoleto. Quizá valga la pena repensar ciertos conceptos y volver la mirada, otra vez, sobre formas y estéticas que dábamos por sentadas. Así quizá podamos recordar que la literatura se retroalimenta de continuo, propone variantes y nuevas categorías para reflexionar sobre ella, pero también sobre nuestra historia y nuestro presente.

\section{Obras citadas}

Abraham, Thomas, Alain Badiou y Richard Rorty. Batallas éticas. Buenos Aires: Nueva Visión, 1995.

Alberca, Manuel. El pacto ambiguo. De la novela autobiográfica a la autoficción. Madrid: Biblioteca Nueva, 2007.

Amar Sánchez, Ana María. Instrucciones para la derrota. Narrativas éticas y políticas de perdedores. Barcelona: Anthropos, 2010.

_ "Máscaras y simulacros: nuevas políticas del sujeto y la narración". Lirico 9 (homenaje a Ana María Barrenechea) 2013. Web. <http://irico.revues.org/1144>.

Badiou, Alain. L'éthique. Essai sur la conscience du mal. Caen: Nous, 2003.

Berger, John. Modos de ver. Barcelona: Gustavo Gili, 1980.

Cabrera Infante, Guillermo. Tres tristes tigres. Barcelona: Seix Barral, 1968.

Chandler, Raymond. "El hombre que amaba a los perros". Asesino en la lluvia. Barcelona: Bruguera, 1978. 63-79.

Donoso Macaya, Ángeles. "Estética, política y el posible territorio de la ficción en 2666 de Roberto Bolaño". Revista Hispánica Moderna 62.2 (2009): 125-142.

Goñi, Javier. "El grito de Trotsky". Babelia. El País. 5 de septiembre de 2009. 
Molero de la Iglesia, Alicia. La autoficción en España: Forge Semprún, Carlos Barral, Luis Goytisolo, Enriqueta Antolín y Antonio Muñoz Molina. Bern: Peter Lang, 2000. Morales-Rivera, Santiago. "La imaginación desmadrada de Juan José Millás: humor y melancolía en La soledad era esto". Revista Hispánica Moderna 64.2 (2011): 129-148. Padura, Leonardo. El hombre que amaba a los perros. México: Tusquets, 2009.

Premat, Julio. Héroes sin atributos. Buenos Aires: Fondo de Cultura Económica, 2009. Rancière, Jacques. Sobre políticas estéticas. Barcelona: Universitat Autònoma, 2005.

— "Las paradojas del arte político". El espectador emancipado.

Buenos Aires: Manantial, 2010. 53-84.

Semprún, Jorge. La segunda muerte de Ramón Mercader. Caracas: Tiempo Nuevo, 1970.

- Veinte años y un día. Barcelona: Tusquets, 2003.

Trotsky, León. La revolución traicionada. Buenos Aires: Claridad, 1938. 